\title{
Eugenesia en movimiento en Argentina entre 1880 y 1970
}

\section{Eugenics on the move in Argentina from 1880-1970}

\author{
Pablo Kopelovich \\ Becario doctoral, Consejo Nacional de Investigaciones Científicas y Técnicas. \\ La Plata - Buenos Aires - Argentina \\ kopelovichp@gmail.com
}

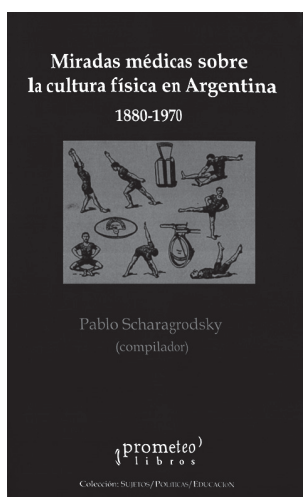

SCHARAGRODSKY, Pablo (Comp.). Miradas médicas sobre la cultura física en Argentina, 1880-1970. Buenos Aires: Prometeo. 2014. 358p.
T a compilación que reseñamos es una publicación de 2014, Lprologada por Dora Barrancos. Consta de 12 artículos realizados por especialistas de distintas disciplinas, como la historia, una de las que se destaca, aunque no faltan los investigadores de áreas como la educación física y las ciencias de la educación. Diversos y rigurosos análisis son presentados en esta obra en torno a los discursos, saberes y prácticas médicas en relación a la cultura física en Argentina entre 1880 y 1970 . En dicho lapso, distintos actores e instituciones pusieron en circulación, distribución, transmisión y producción, un conjunto heterogéneo de sentidos vinculados con el cuerpo orgánico y su normal funcionamiento, y con temas y problemas que excedieron el universo biológico, como moral, belleza, sexualidad, deseo, masculinidad y feminidad, entre otros. De este modo, se consideran diferentes ámbitos en los que se realizan prácticas corporales, haciéndose referencia a las diversas ramas de la medicina que contribuyeron a controlar, administrar, gobernar, los cuerpos en movimiento.

En ese marco, estimamos que entre los importantes aportes que realiza la obra reseñada se destaca, especialmente, la conexión entre eugenesia y cultura física en el contexto de una resignificación, apropiación a las realidades latinoamericanas de ciertos postulados y discusiones provenientes del continente europeo sobre la degeneración y la regeneración racial. Se trata de un período en el que se producen profundas y vertiginosas transformaciones sociales resultado, en parte, de las guerras mundiales. Es decir, pese a ser una cuestión ya analizada en diferentes producciones de Argentina y Latinoamérica (Di Liscia, 2005; Aisenstein, Scharagrodsky, 2006; Olaechea, 2008; Romaniuk, 2013, entre otros), esta compilación realiza su contribución al campo al profundizar el estudio del mejoramiento de la raza a través del ejercicio físico en distintos espacios donde confluyen discursos y prácticas vinculadas al ámbito médico. Entre estos espacios, se encuentran, por ejemplo, las colonias de vacaciones para niños débiles, el deporte femenino, y la Asociación Argentina de Biotipología, Eugenesia y Medicina Social (en adelante, AABEMS). Pensar a 
dicha asociación, enclave de la cultura física promovida, es, sin dudas, un pasaje a considerar del texto de Andrés Reggiani. ${ }^{1}$ Así, centrarse en las significaciones de ciertas prácticas corporales tendientes al mejoramiento de la raza puede pensarse como un pretexto para abordar procesos sociales más amplios.

Reggiani (Universidad Torcuato Di Tella) refiere a que en Londres, en 1904, Francis Galton, fundador de la eugenesia, define a ésta como la ciencia que se ocupa de todas las influencias que mejoran las cualidades innatas de la raza. De esta forma, lo que la diferencia de otras disciplinas biomédicas es el lugar central ocupado por la degeneración como explicación totalizadora o meta-relato de la evolución de la sociedad occidental bajo las condiciones de la modernidad. Estas lecturas se llevan a cabo en el contexto de entender que todos los problemas tenían una solución racional y científica. Entonces, para el caso argentino, las preguntas por la calidad y aptitud de la población se vincularon a la percepción social del inmigrante como factor "problemático" para cuya asimilación se requiere el auxilio de la ciencia. Es en ese marco de incertidumbre que, siguiendo al autor, el médico Enrique Romero Brest sienta las bases de una pedagogía del cuerpo cuyo objetivo es la formación integral de una ciudadanía republicana. De esta manera, la educación física es tema de consenso durante la primera Conferencia Panamericana de Eugenesia y Homicultura, celebrada en La Habana (Cuba), en 1927. Allí se aboga por la adopción de políticas nacionales que fomenten las prácticas físicas entre la población y su enseñanza obligatoria en las escuelas. En ese contexto, volviendo al caso argentino, se destaca la AABEMS, creada en 1932 y considerada el referente más importante de la eugenesia en el continente latinoamericano. Desde dicha institución, pese a pensarse el mejoramiento de la población desde una óptica lo más amplia posible, se destacaron los biotipólogos. Así, "los esfuerzos por encontrar una fórmula 'correlacionadísima' que ponderase la herencia, la forma externa (morfología), el temperamento humoral y funcional, el carácter afectivo y volitivo, y la inteligencia generaron una plétora de taxonomías y términos de difícil aplicación para los no iniciados" (Reggiani, 2014, p.45-46). Como ciencia aplicada, la biotipología ve en las prácticas físicas uno de los ámbitos ideales para difundir su prédica. Sin embargo, el involucramiento de la AABEMS fue aún más claro en el campo de la medicina del deporte, que se expande ya desde la década del 1920: los biotipólogos insistieron en la necesidad de que las organizaciones deportivas contaran con servicios médicos capacitados para determinar la pauta de la constitución físico-psíquica individual más apta para la práctica de un determinado deporte. Así, este autor plantea que el campo de la cultura física y de la eugenesia se "fertilizaron" mutuamente a través de propuestas que hacían de la práctica metódica de actividad física un dispositivo central de regeneración.

De este modo, según indica Andrea Torricella (Universidad Nacional de Mar del Plata) en su artículo, la escuela biotipológica de mayor influencia fue la italiana representada por Nicola Pende, lo que se plasma en la creación de la mencionada AABEMS de la mano de los médicos Arturo Rossi y Octavio López.

Asimismo, Patricia Anderson (Universidad de Belgrano y Universidad Nacional de Tres de Febrero) - que se centra en el deportismo, la salud y la feminidad en el país en cuestión entre 1900 y 1945 - plantea que se consideraba en esa época que "la actividad física practicada de una forma moderada y controlada, dirigida y supervisada por expertos, 
podía mejorar la salud corporal y psíquica de las mujeres, ayudando así al desarrollo de la 'raza' argentina" (Anderson, 2014, p.84). Es decir, las prácticas deportivas femeninas se justificaban porque contribuían a optimizar la capacidad reproductiva, transformando a la mujer en una mejor madre. Entonces, se lleva a cabo una supervisión y control del cuerpo femenino por parte de un grupo heterogéneo de especialistas de la salud, entre otras cosas, porque se consideraba que las mujeres de vida sedentaria presentaban consecuencias graves para la sociedad, ya que eran ellas las responsables del bienestar físico y psíquico de las futuras generaciones, que heredarían sus virtudes. Este tipo de construcciones desde la medicina alimentó cierta desigualdad de género, estableciendo determinados deportes y prácticas corporales como adecuados o inadecuados para las mujeres.

Queremos destacar, también, la producción de Lucía Lionetti (Universidad Nacional del Centro), quien refiere a que en este país la eugenesia fue fundamentalmente de tipo preventiva. Así, la infancia en los primeros años del siglo XX - que paulatinamente es escolarizada - fue convertida en el futuro de la nación, devenida en el espacio estratégico donde convergían los peligros más terribles de una posible degeneración racial, tanto como las ilusiones y esperanzas sociales en el progreso y el bienestar colectivos (Castillo Troncoso, citado en Lionetti, 2014). Así, desde el Estado se procura identificar a los "niños débiles" y derivarlos a las escuelas y colonias de vacaciones, creadas especialmente para ellos, donde se practica educación física consistente en juegos, ejercicios libres y ejercicios gimnásticos. Allí, nuevamente se hace muy presente la mirada médica sobre los cuerpos en movimiento con el fin de mejorar la raza, esta vez, a partir de la ficha médica: "una experiencia por la que pasaron aquellos escolares que, por su condición de pobres, fueron portadores de un cuerpo considerado en riesgo al que había que corregir para que no afectara al cuerpo social" (Lionetti, 2014, p.215).

Así, entendemos como relevante a esta producción, ya que es la primera que logra, de manera clara y exhaustiva, problematizar históricamente las prácticas corporales (deportes, gimnasias, juegos, danzas folclóricas, colonias de vacaciones, campamentismo, prácticas de tiro) abordadas desde el heterogéneo discurso médico en Argentina, en el marco del contexto latinoamericano. Ello es alcanzado en los distintos artículos a partir de la consideración de los debates que otros investigadores han realizado y del análisis de variadas fuentes: actas de congresos, artículos académicos, planes y programas escolares, normativas oficiales, artículos periodísticos, fotografías, entre otras. Las distintas obras compiladas confluyen en los puntos mencionados, aunque hacen hincapié en distintas cuestiones como son, por ejemplo, el ámbito castrense (Méndez), la pertenencia política de los actores (Martínez Mazzola), las colonias de vacaciones (Diego Armus), el deporte adaptado (Ferrante), la religión (Frescia y Nicoletti), la educación (Scharagrodsky, Aisentsein), y la mujer (Anderson).

Por todo ello, recomendamos la lectura de esta compilación a un heterogéneo público académico (historiadores, profesores e investigadores en educación física, profesionales de la salud, cientistas de la educación, especialistas en cuestiones de género, investigadores de las ciencias sociales en general) y a todo aquel que pretenda interiorizarse en el campo de las prácticas corporales en su relación con un discurso médico fuertemente prescriptivo y proscriptivo, en el afán de continuar profundizando el estudio de esta interesante problemática sobre la que queda mucho por pensar. 
${ }^{1}$ Autores como Kirsch (2006) y Navarlaz (2008) ya habían abordado esta asociación, aunque desde otra clave analítica.

\section{REFERENCIAS}

AISENSTEIN, Ángela; SCHARAGRODSKY, Pablo. Tras las huellas de la educación física escolar argentina: cuerpo, género y pedagogía, 1880 1950. Buenos Aires: Prometeo. 2006.

ANDERSON, Patricia.

"Mens sana in corpore sano": deportismo, salud y feminidad en Argentina, 1900-1945. In: Scharagrodsky, Pablo (Comp.). Miradas médicas sobre la cultura física en Argentina, 1880-1970. Buenos Aires: Prometeo. p.83-100. 2014.

DI LISCIA, María Silvia.

Colonias y escuelas de niños débiles: los instrumentos higiénicos para la eugenesia, primera mitad del siglo XX en Argentina. In: Di Liscia, María Silvia; Bohoslavsky, Ernesto (Ed.). Instituciones y formas de control social en América Latina, 1840-1940: una revisión. Buenos Aires: Prometeo. p.93-113. 2005.

KIRSCH, Úrsula.

La revista Anales de Biotipología, Eugenesia y Medicina Social. In: Jornadas de Investigación, 11., 2006, Buenos Aires. Acta Académica.

Disponible en: https://www.aacademica. org/000-029/332.pdf. Acceso en: 16 abr. 2018. 2006.

\section{LIONETTI, Lucía.}

Discursos y prácticas de docilización sobre las corporalidades anormales en Argentina en los albores del siglo XX. In: Scharagrodsky, Pablo (Comp.). Miradas médicas sobre la cultura física en
Argentina, 1880-1970. Buenos Aires: Prometeo. p.193-219. 2014.

NARVALAZ, Vanesa Eva.

Los Anales de Biotipología, Eugenesia y

Medicina Social y un cambio en la nosografía psiquiátrica relacionado con el origen de la psicología en la Argentina. Revista Anuario de Investigaciones, v.15, p.151-159. 2008.

OLAECHEA, Belén.

Debilidad, eugenesia y actividad física aprincipios del siglo XX. In: Jornadas de Cuerpo y Cultura de la Universidad Nacional de La Plata, 2008, La Plata. Acta Académica. Disponible en: https://www.aacademica.org/000-021/45. pdf. Acceso en: 16 abr. 2018. 2008.

REGGIANI, Andrés.

Eugenesia y cultura física: tres trayectorias históricas: Francia, Gran Bretaña y Argentina. In: Scharagrodsky, Pablo (Comp.). Miradas médicas sobre la cultura física en Argentina, 1880 1970. Buenos Aires: Prometeo. p.17-58. 2014.

ROMANIUK, Susana.

Discapacidad, cultura física y eugenesia en la revista Viva Cien Años, 1934-1945. In: Congreso Argentino de Educación Física y Ciencias, 10., 2013, La Plata. Sedici. La Plata: UNLP. Disponible en: http://sedici.unlp.edu.ar/ handle/10915/39409. Acceso en: 16 abr. 2018. 2013. 